\title{
Treatment of thoracic aortic aneurysm
}

\author{
Wilbert S. Aronow \\ Department of Medicine, Westchester Medical Center and New York Medical College, Valhalla, New York, USA \\ Correspondence to: Wilbert S. Aronow, MD, FACC, FAHA. Professor of Medicine, Cardiology Division, Westchester Medical Center and New York \\ Medical College, Macy Pavilion, Room 141, Valhalla, NY 10595, USA. Email: wsaronow@aol.com.
}

Submitted Nov 17, 2017. Accepted for publication Jan 04, 2018.

doi: 10.21037/atm.2018.01.07

View this article at: http://dx.doi.org/10.21037/atm.2018.01.07

The diameter of thoracic aortic aneurysm (AA) is at least 1.5 times that of a normal thoracic aorta (1). Sixty percent of thoracic AAs occur in the aortic root and/or the ascending aorta, $40 \%$ occur in the descending aorta, $10 \%$ occur in the aortic arch, and 10\% occur in the thoracoabdominal aorta (2). Patients with thoracic AA are at increased risk for aortic dissection if they have high blood pressure, especially not controlled, dyslipidemia, smoking, use of cocaine and other stimulants which increase aortic wall stress, weight lifting, trauma, aortic coarctation, pheochromocytoma, and disorders with abnormalities of the aortic media (3). Other causes for thoracic aortic dissection are pregnancy, polycystic renal disease, chronic use of corticosteroids or immunosuppressant drugs, and aortic wall infections (3).

Persons with thoracic AA must be counseled about smoking cessation and referred to a smoking cessation program with either use of nicotine replacement, varenicline, or bupropion (3). These patients must also avoid exposure to passive smoking. Current cigarette smoking is a major risk factor for development of thoracic AA.

Dyslipidemia must be treated. Atorvastatin 40 to $80 \mathrm{mg}$ daily or rosuvastatin 20 to $40 \mathrm{mg}$ daily should be administered to persons with thoracic AA (4). Of 649 persons, mean age 70.3 years, with a thoracic AA, 147 (23\%) were treated with statins (5). At a median followup of 3.6 years, statins reduced all-cause mortality by $32 \%$ from $33 \%$ to $20 \%$ and the composite end-point of allcause mortality, rupture, dissection, or repair $28 \%$ from $75 \%$ to $59 \%$ (5). In another study of 1,560 patients, mean age 63 years, with thoracic AAs, 369 (24\%) were treated with statins (6). The patients treated with statins had a $44 \%$ reduction in surgery within 10 years (6). In this study, use of angiotensin receptor blockers reduced surgery by $34 \%$, and use of beta blockers reduced surgery by $31 \%$ (6)
Hypertension must be controlled to decrease myocardial infarction, stroke, heart failure, death from cardiovascular causes, and aortic dissection (3,7-12). The blood pressure in persons with thoracic AA should be lowered to less than 130/80 mmHg. A beta blocker plus an angiotensinconverting enzyme inhibitor or angiotensin receptor blocker should be administered to these persons $(3,7)$. Beta blockers lower blood pressure and also reduce peak left ventricular ejection rate. By decreasing left ventricular $\mathrm{dP} / \mathrm{dt}$ and decreasing shear stress, beta blockers decrease the rate of aortic dilatation (12). Beta blockers also decrease $\mathrm{dP} / \mathrm{dt}$ and shear stress in the aorta (12). Persons with Marfan's syndrome should also be treated with beta blockers $(3,13)$ and with losartan $(3,14)$ to lower aortic dilatation.

If there are symptoms suggesting thoracic AA expansion, surgical intervention should be considered. If the ascending thoracic aorta or aortic sinus diameter is $5.5 \mathrm{~cm}$ or more in an asymptomatic surgical candidate who has a degenerative thoracic AA, chronic aortic dissection, intramural hematoma, penetrating atherosclerotic ulcer, mycotic aneurysm, or pseudoaneurysm, surgery should be performed (3). Asymptomatic persons with genetic conditions such as Marfan's syndromes should have elective surgery if their diameters are 4.0 to $5.0 \mathrm{~cm}$ depending on the disorder to prevent acute dissection or rupture $(3,15,16)$. Asymptomatic women who have Marfan's syndrome desiring to become pregnant should have surgical intervention to replace their aortic root and ascending aorta if their ascending thoracic aorta diameter is greater than $4.0 \mathrm{~cm}$ (3). Asymptomatic persons with Marfan's syndrome should be treated with surgical intervention if their ascending thoracic aortic diameter is $5.0 \mathrm{~cm}$ or more and with $<5.0 \mathrm{~cm}$ if there is a family history of dissection or an increase in ascending thoracic aortic diameter greater 
than $0.5 \mathrm{~cm}$ per year (3). Asymptomatic persons who have Loeys-Dietz syndrome should be treated with surgical intervention if their ascending thoracic aortic diameter is $\geq 4.2 \mathrm{~cm}$ by transesophageal echocardiography or 4.4 to $4.6 \mathrm{~cm}$ by cardiac computed tomography or cardiac magnetic resonance (3). If the increase in the ascending thoracic aortic diameter is greater than $0.5 \mathrm{~cm}$ per year in an asymptomatic person with a diameter below $5.5 \mathrm{~cm}$, surgical intervention should be performed (3). Asymptomatic persons with bicuspid aortic valve should have surgical intervention if the diameter of their aortic sinuses or ascending thoracic aorta is $>5.5$ or $>5.0 \mathrm{~cm}$ with a family history of aortic dissection or an increase in diameter $\geq 0.5 \mathrm{~cm} /$ year (17). The ascending thoracic aorta should be replaced in persons with bicuspid aortic valve having aortic valve surgery if their ascending thoracic aorta diameter is $>4.5 \mathrm{~cm}$ (17).

If thoracic aorta dissection develops, decrease aortic shear stress and decide which persons should have surgical intervention or endovascular repair (3). Beta blockers are the initial drug of choice for lowering blood pressure, ventricular rate, $\mathrm{dP} / \mathrm{dt}$, and stress on the aorta $(3,18,19)$. Systolic blood pressure should be lowered to 100 to $120 \mathrm{mmHg}$ and the ventricular rate lowered to $<60$ beats/minute by intravenous propranolol, metoprolol, labetalol, or esmolol $(3,19)$. Intravenous verapamil or diltiazem may be administered to persons intolerant to treatment with beta blockers $(3,19)$. If more antihypertensive drugs are needed to lower the systolic blood pressure to 100 to $120 \mathrm{~mm} \mathrm{Hg}$, treat these patients with intravenous sodium nitroprusside, nicardipine, nitroglycerin, or fenoldopam $(3,20)$.

Seventy-eight of 130 patients $(60 \%)$ with aortic dissection type $\mathrm{B}$ were treated with medical treatment only (8). Seventy-one of these 78 patients (91\%), mean age 64 years, were discharged from the hospital. During follow-up, hypertension was treated with beta blockers in 51 patients and with other antihypertensive drugs in 20 patients. During 4.2-year mean follow-up, 9 of 51 patients $(18 \%)$ treated with beta blockers and 11 of 20 patients $(55 \%)$ treated with other antihypertensive drugs needed dissection-related surgery (8).

A total of 1,301 patients with acute aortic dissection (722 with type A dissection and 579 with type B dissection) were followed for $\leq 5$ years (9). Treatment with beta blockers improved survival in patients with type A dissection and in patients with type B dissection (9). Treatment with calcium channel blockers improved survival in those with type B dissection (9).

\section{Acknowledgements}

None.

\section{Footnote}

Conflicts of Interest: The author has no conflicts of interest to declare.

\section{References}

1. Norman PE, Powell JT. Site specificity of aneurysmal disease. Circulation 2010;121:560-8.

2. Isselbacher EM. Thoracic and abdominal aneurysms. Circulation 2005;111:816-28.

3. Hiratzka LF, Bakris GL, Beckman JA, et al. ACCF/AHA/ AATS/ACR/ASA/SCA/SCAI/SIR/STS/SVM guidelines for the diagnosis and management of patients with thoracic aortic disease. J Am Coll Cardiol 2010;55:e27-129.

4. Stone NJ, Robinson J, Lichtenstein AH, et al. 2013 ACC/ AHA guideline on the treatment of blood cholesterol to reduce atherosclerotic cardiovascular risk in adults: a report of the American College of Cardiology/American Heart Association Task Force on Practice Guidelines. J Am Coll Cardiol 2014;63:2889-934.

5. Jovin IS, Duggal M, Ebisu K, et al. Comparison of the effect on long-term outcomes in patients with thoracic aortic aneurysms of taking statins versus not taking a statin drug. Am J Cardiol 2012;109:1050-4.

6. Stein LH, Berger J, Tranquilli M, et al. Effect of statin drugs on thoracic aortic aneurysms. Am J Cardiol 2013;112:1240-5.

7. Aronow WS, Fleg JL, Pepine CJ, et al. ACCF/AHA 2011 expert consensus document on hypertension in the elderly: a report of the American College of Cardiology Foundation Task Force on Clinical Expert Consensus Documents. Developed in collaboration with the American Academy of Neurology, American Geriatrics Society, American Society for Preventive Cardiology, American Society of Hypertension, American Society of Nephrology, Association of Black Cardiologists, and European Society of Hypertension. J Am Coll Cardiol 2011;57:2037-114.

8. Genoni M, Paul M, Jenni R, et al. Chronic $\beta$-blocker therapy improves outcome and reduces treatment costs in chronic type B aortic dissection. Eur J Cardiothorac Surg 2001;19:606-10.

9. Suzuki T, Isselbacher EM, Nienaber CA, et al. Typeselective benefits of medications in treatment of acute 
aortic dissection (from the International Registry of Acute Aortic Dissection (IRAD)). Am J Cardiol 2012;109:122-7.

10. Lu H, Rateri DL, Cassis LA, et al. The role of the reninangiotensin system in aortic aneurysmal diseases. Curr Hypertens Rep 2008;10:99-106.

11. Goldfinger JZ, Halperin JL, Marin Ml, et al. Thoracic aortic aneurysm and dissection. J Am Coll Cardiol 2014;64:1725-39.

12. Danyi P, Elefteriades JA, Jovin IS. Medical therapy of thoracic aortic aneurysms. Are we there yet? Circulation 2011;124:1469-76.

13. Shores J, Berger KR, Murphy EA, et al. Progression of aortic dilatation and the benefit of long-term betaadrenergic blockade in Marfan's syndrome. N Engl J Med 1994;330:1335-41.

14. Brooke BS, Habashi JP, Judge DP, et al. Angiotensin II blockade and aortic-root dilation in Marfan's syndrome. N Engl J Med 2008;358:2787-95.

Cite this article as: Aronow WS. Treatment of thoracic aortic aneurysm. Ann Transl Med 2018;6(3):66. doi: 10.21037/ atm.2018.01.07
15. Kouchoukos NT, Dougenis D. Surgery of the thoracic aorta. N Engl J Med 1997;336:1876-89.

16. Elefteriades JA. Natural history of thoracic aortic aneurysms: indications for surgery, and surgical versus nonsurgical risks. Ann Thorac Surg 2002;74:S1877-80; discussion S1892-8.

17. Nishimura RA, Otto CM, Bonow RO, et al. 2014 AHA/ ACC guideline for the management of patients with valvular heart disease: a report of the American College of Cardiology/American Heart Association Task Force on Practice Guidelines. J Am Coll Cardiol 2014;63:e57-185.

18. Braverman AC. Acute aortic dissection. Clinician update. Circulation 2010;122:184-8.

19. Tsai TT, Nienaber CA, Eagle KA. Acute aortic syndromes. Circulation 2005;112:3802-13.

20. Eggebrecht H, Schmermund A, von Birgelen C, et al. Resistant hypertension in patients with chronic aortic dissection. J Hum Hypertens 2005;19:227-31. 